\title{
Better Knowledge Need Not Affect Behavior: A Randomized Evaluation on the Demand for Lottery Tickets in Rural Thailand
}

Juliane Zenker, Andreas Wagener, Sebastian Vollmer

CID Working Paper No. 282

May 2014

(C) Copyright 2014 Zenker, Juliane; Wagener, Andreas; Vollmer, Sebastian; and the President and Fellows of Harvard College
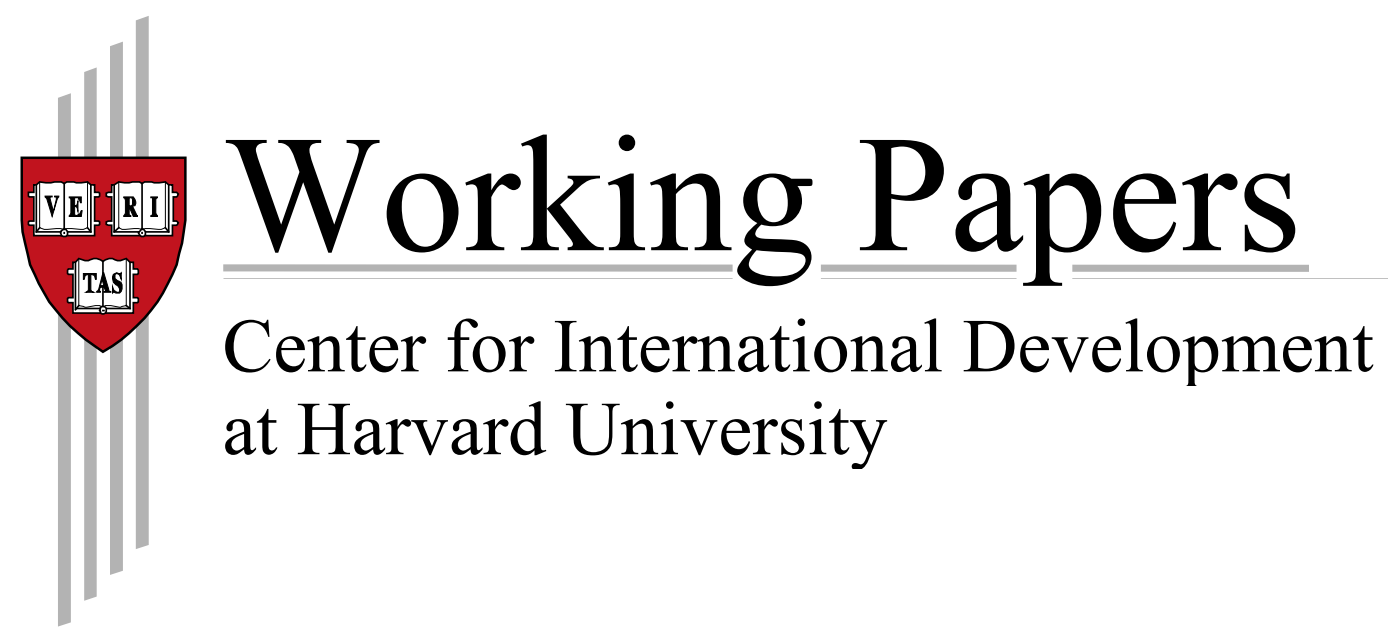


\title{
Better knowledge need not affect behavior: a randomized evaluation on the demand for lottery tickets in rural Thailand*
}

\author{
Juliane Zenker ${ }^{\dagger} \quad$ Andreas Wagener ${ }^{\ddagger} \quad$ Sebastian Vollmer ${ }^{\S}$
}

\begin{abstract}
Many rural Thai households spend significant shares of their annual expenditure on lottery tickets while having poor knowledge about the properties of the game and upwardly biased prospects of winning the jackpot. By randomly informing households on the actual probability distribution of the Thai Government Lottery we test whether improved knowledge reduces lottery participation. Our intervention exogenously induces more precise perceptions of the lottery's odds in the treatment group. We show, however, that the willingness to pay for lottery tickets is not affected by that.
\end{abstract}

JEL Codes: D83, C93, O12, D12.

Keywords: State Lottery, Gambling, Information Campaign, Knowledge, Thailand, Field Experiment.

*This research was funded by the German Research Council (DFG) in its RTG 1723. The authors thank Marcela Ibanez and Juanita Vasquez as well as participants of seminars at the Harvard Center for Population and Development Studies for valuable comments and suggestions, and Lukas Menkhoff, Hermann Waibel, Antonia Grohmann, and Sahra Sakah for their support.

†University of Hannover, DFG-RTG 1723 "Globalization and Development", Koenigsworther Platz 1, 30167 Hannover, Germany; \& University of Goettingen, Department of Economic Sciences, Platz der Goettinger Sieben 5, 37073 Goettingen, Germany. E-mail: zenker@glad.uni-hannover.de

$\ddagger$ University of Hannover, Institute of Social Policy, Koenigsworther Platz 1, 30167 Hannover, Germany. E-mail: wagener@sopo.uni-hannover.de

$\S$ University of Goettingen, Department of Economic Sciences, Platz der Goettinger Sieben 3, 37073 Goettingen, Germany; \& Harvard School of Public Health, Department of Global Health and Population, Boston MA, USA. E-mail: svollmer@uni-goettingen.de 


\section{Introduction}

In expected value terms, playing the lottery is a waste of money. Yet it is a popular pastime all around the world, particularly among poorer people. This is surprising considering that potential returns of extra spending on nutrition, health or schooling are large. Various explanations have been offered for why demand for lottery tickets remains so puzzlingly high (at least from the viewpoint of a sober calculator): lotteries nourish dreams and hopes for better lives (Matheson and Grote, 2004); they offer fun and excitement (Kocher, Krawczyk, and van Winden, 2013); they are a social affair (Rogers and Webley, 2001); their proceeds often go to the funding of public goods and charities etc. Another common explanation, however, for the popularity of lotteries is that players hold distorted perceptions of the probability distribution of gains. People are not aware of the true distribution of net gains and losses of purchasing lottery tickets or harbor illusions and biases that interfere with an objective probability assessment. ${ }^{1}$ Consequently, they buy too many lottery tickets, as compared to what an objective assessment of the winning odds would advise them. One implication of this reasoning is that eliminating the lack of knowledge and the misperceptions of the odds of the game will lead to a better informed decision, viz., a reduction in ticket purchases.

We test this hypothesis in a randomized-controlled experiment with rural households in Northeastern Thailand. In our intervention we familiarize participants in the treatment group with the probability distribution of the Thai Government Lottery (TGL) and visualize its winning and losing probabilities. Although we find that knowledge on the odds of the game and the willingness to pay for lottery tickets are negatively correlated in the control group, by and large, we reject the hypothesis that playing the lottery is caused by a lack of knowledge alone. More precisely, our experiment shows that

\footnotetext{
${ }^{1}$ Misconceptions include the gambler's fallacy, the near-miss fallacy, illusion of control and many others. In addition, heavy media presence of winners and the limited observational experience of each player lead to availability bias in the assessment of lottery odds. For good overviews see e.g. Tversky and Kahneman (1974), Clotfelter and Cook (1990), Kocher, Krawczyk, and van Winden (2013).
} 
(i) teaching people about the true return distribution improves their understanding and knowledge about the (adverse) odds of lotteries, while

(ii) this improved knowledge does not translate into changes in behavior: demand for lottery tickets of treated individuals does not significantly differ from demand of the untreated.

Our study contributes to a number of strands in the literature:

First, we add to the understanding of lottery purchases of the poor by changing knowledge exogenously with a randomized treatment. In general, evidence on the relationship of lottery knowledge and behavior is mixed. Stearns and Borna (1995), for instance, claim that consumers will change their behavior once they receive adequate and complete information on the expected value of the lottery ticket. ${ }^{2}$ Wagenaar (1988), in contrary, was the first to presume that there might be no (strong) correlation between lottery knowledge and behavior but finds that the size of the jackpot is a main driver for participation. Rogers and Webley (2001) find that odds knowledge is not correlated with lottery behavior, while beliefs in skills and luck as well as optimism are. Even less evidence exists for the relationship of odds knowledge and lottery behavior of the poor. One of the few studies by Kearney (2005) finds that knowledge determines lottery participation for poor households in the United States. If a lack of lottery knowledge is really one of the main drivers for lottery participation among the poor in the United States, then there is reason to believe that the underlying determinants of this knowledge gap are even more present for poor households in the developing world. For instance, quality and duration of

\footnotetext{
${ }^{2}$ The authors inform lottery customers on the expected value of their just bought ticket shortly after the purchase and ask whether the respondent would be willing to buy a ticket with similar properties again. They find that the reported intentions of the study subjects to buy the ticket again are smaller than the actual amount of tickets bought by those subjects. However, their study design suffers from several short comings. The authors do not measure behavior but only ask lottery customers for their purchase intentions, which in general might greatly differ from actual actions. In particular, it is very likely that the treatment induced a (short term) change in the perception of social norms on lottery participation which might have led the respondents to understate his or her purchase intentions to please the enumerator. As the authors did not include a placebo control group, no clear differentiation between these effects and a potential effect of the provided information can be made.
} 
schooling are on average lower and the ability to process very small and very large numbers as well as the understanding of percentage calculation is rather moderate to low on average for many poor individuals in developing countries. In addition, internet coverage and usage is still rare in poor rural areas, making it almost impossible to access objective information on the winning and losing probabilities of the lottery. Apart from neighbor's and own experience, for evaluating lottery odds television is the main source of information which often greatly (in the case of Thailand even excessively) advertises the state lottery and its winners. Exploring the relationship of knowledge and lottery participation in our control group, indeed, we find a significantly negative correlation of lottery knowledge and participation. Of course, many factors may affect gambling decisions, ranging from entertainment seeking to addiction. Nevertheless, these results suggest that at least for some of the households in our sample additional information might be key to make better purchase decisions. However, analyzing the results of the exogenous change in knowledge induced by our treatment, we challenge the finding in Kearney (2005) and the reasoning in many other studies that knowledge determines lottery participation. We provide evidence that lack of probabilistic knowledge about the game does not seem to be the main driver or preventer of playing the lottery.

Second, we add support to the research in judgement and decision-making that investigates the link between knowledge and behavior. A quickly growing literature on randomized-controlled information campaigns evolved in recent years, documenting the effect of information on knowledge and behavioral outcomes in real life settings. Some pioneering studies show that simple information interventions e.g. on retirement plans (Duflo and Saez, 2003), returns to education (Jensen, 2010), calorie intake (Wisdom, Downs, and Loewenstein, 2010), sexually transmitted infections (Dupas, 2011) and sexual-health education (Chong, Gonzalez-Navarro, Karlan, and Valdivia, 2013) might be very efficient tools in improving important economic, education and health decisions. However, a number of studies in economics and cognitive science report a so called knowledge behavior gap. Choices are often not driven by knowledge but by different aspects like beliefs, personal traits, situations, habits, or emo- 
tions. If this is true, then the plausible conjecture that improved knowledge leads to better (or at least different) decisions does not necessarily work. A number of information campaigns, training programs and educational interventions were targeted (successfully) to improve understanding and knowledge - without, however, affecting behavior. E. g., providing information on potentially positive or negative effects of fertilizers improved farmers' understanding on benefits or hazards associated with fertilizers - but did not affect the actual (mis-)use of fertilizers (Hornik, 1989). Likewise, a recent intervention using messaging to inform about and to encourage recycling did not lead to a significant change in recycling behavior in Peru (Chong, Karlan, Shapiro, and Zinman, 2013). A messaging intervention by (Jamison, Karlan, and Raffler, 2013) in Uganda aimed at improving sexual health knowledge to shift individuals towards safer sexual behavior. However, the authors find that the improved access to information did not increase knowledge neither shifted perception of norms or behavior to less risky sexual activities. Furthermore, a training program for start-up entrepreneurs in Peru improved knowledge on running business - but did not enhance sales and profits (Karlan and Valdivia, 2011). Our study reports a similar phenomenon for an information intervention on lotteries. We will briefly discuss our findings and information campaigns in general in the light of the theory of planned behavior (TPB), and suggest that it might serve as a powerful framework and should be taken into account by economic researchers when planning information campaigns designed to trigger behavioral changes.

Third, we add evidence to the literature on consumption behavior of poor households in developing countries by pointing out that expenditures for lottery and potentially other forms of gambling seem to be an important part of many poor household's budgets. It has been noted before that the poor (surprisingly or even understandably) do not tend to spend all of their money on food and non-food items they greatly need. Instead, entertainment related spending, i.e., for alcohol, tobacco and festivals as well as for radios and TV sets, accounts for an important share of many poor household's budgets (Banerjee and Duflo, 2007). To our knowledge, however, not much evidence 
has been provided for gambling expenditure of the poor in the developing world, although we know from a few studies on the United States that poor households tend to devote a relatively large share of their income on lottery tickets. ${ }^{3}$ We will provide first evidence to close that gap by exploring the lottery behavior of rural Thai households. In our sample, playing the TGL is popular (as are illegal lotteries and gambling) while roughly one third of the households live below the national poverty line. ${ }^{4}$ About $58 \%$ of our sample did engage in lottery activity at least once over the past 12 months, devoting an average share of about $3 \%$ of their annual expenditures to legal and illegal lottery participation. To explore the extent of alarming participation in our sample, we classify the top quintile of lottery players in terms of lottery expenditure share as "heavy players". These 97 participants, roughly $12 \%$ of our sample, account for about $65 \%$ of the lottery expenditure in our sample. ${ }^{5}$ Roughly $27 \%$ of these households live below national poverty line. In light of these findings, we will pay special attention to heavy players when discussing our treatment effects.

The rest of this paper is organized as follows: In Section 2 we describe data

\footnotetext{
${ }^{3}$ Clotfelter and Cook (1989), for instance, finds for households in the United States that the average person earning under $\$ 10,000$ annually spent $2 \%$ of his household income on lottery tickets, while individuals with incomes above $\$ 40,000$ spent less than $0.5 \%$ on tickets. This is why critics refer to state lotteries as a form of regressive taxation (Stearns and Borna, 1995). Moreover, Kearney (2005) provides evidence that expenditures on lottery tickets crowd out expenditures on food and other necessities for low-income households in the United States.

${ }^{4}$ According to the Thailand Office of the National Economic and Social Development Board the national poverty line in Thailand was 29,046 Baht (PPP \$ 1442) per capita and year in 2011. We use this threshold as numbers for 2013 are not available as of now. Taking inflation between the two periods into account, the share of individuals living below national poverty line is actually likely to be higher than one third of our sample.

${ }^{5}$ These descriptive statistics are based on baseline data including all (legal and illegal) lottery activities, where approximately a quarter is spend on tickets of the TGL and three quarters are devoted to illegal lottery games. These numbers exclude all other gambling activities like dice and card games, bets on cockfighting, etc. Illegal lottery is secretly organized in local communities and usually based on bidding on the last two or three digest of the jackpot winning ticket numbers. Stakes and winning odds can be quite different across communities and we therefore decide to base our intervention on the official state lottery game which the majority of our participants is most familiar with. However, we are confident that our results are transferable to the illegal forms of lottery play.
} 
sources and provide baseline characteristics of our sample. Furthermore, we explore the relationship of lottery knowledge and behavior in the baseline data. In Section 3 we describe our intervention design. In Section 4 we present results on the impact of the intervention on lottery probability assessment and willingness to pay for participation. In Section 5 we discuss our results and conclude.

\section{Data and background}

\section{$2.1 \quad$ Data}

Background. Our study was carried out in rural areas of Ubon Ratchathani, a province in Northeastern Thailand, where roughly half of the households still live below the national poverty line. The region serves as a good testing ground for our information intervention because playing the Thai Government Lottery (TGL) is popular while accurate and complete information about its winning and losing probabilities is not easily accessible. Tickets are mainly sold by untrained mobile vendors who travel on motor bikes through the countryside. The TGL provides some information on the back of the ticket, i.e., how many tickets will win in each prize category. This information is incomplete, however, as the total number of issued tickets is missing. In sum, the expected (net) payoff of a ticket is not obvious to participants.

Data collection. We use baseline data from an extensive household panel survey project conducted in South East Asia. ${ }^{6}$ The data set solicits household

\footnotetext{
${ }^{6}$ The panel study is carried out in the project "Impact of shocks on the vulnerability to poverty - consequences for the development of emerging Southeast Asian economies" (FOR 756, German Research Foundation). A three-stage cluster sampling strategy was applied, selecting two villages each in 49 sub-districts representative for rural population of Ubon Ratchathani in 2007. In each of the 98 sampled villages, ten households were randomly selected. In the 5th wave in 2013 it was possible to interview about $90 \%$ of these 980 initially sampled households. For a detailed description on the sampling strategy see (Hardeweg, Klasen, and Waibel, 2013).
} 
member characteristics, (lottery) expenditure and a rich variety of information on financial behavior and experienced shocks, which might interact with lottery participation. We use this baseline data to test whether important characteristics are balanced between treatment and control group and to check for the robustness of our results.

The intervention was conducted in August 2013, a few months after the 5th wave of the household panel survey. A total of 853 households participated. Supplementing the data from the household survey, we collected baseline characteristics for all participants, including attitudes towards lotteries, basic math skills and risk attitude. In 49 (out of 98) randomly selected villages participants underwent an information treatment on the Thai Government Lottery shortly before the end of their interview (for details see Section 3$).{ }^{7}$ In the final part of the interview, we measure all participant's knowledge of key features of the TGL and their willingness to pay for participation. We describe these measures in Section 2.2.

Randomization. Randomization into treatment and control groups was carried out blindly by the authors. Selection was conducted at the village level to avoid information spill-overs between treatment and control groups within one village. All villages had an equal chance of being selected into the treatment group. The intervention was carried out by local enumerators with one of the authors or research fellows being present in all cases to ensure compliance. We cannot fully eliminate the possibility that information had spread between villages; yet this is rather unlikely: most of the surveyed villages are far away from each other. For neighboring villages interviews were usually carried out simultaneously and all participants were staying at the interview

\footnotetext{
${ }^{7}$ In general enumerators were instructed to select the household member (usually the household head) to participate in the interview and intervention, who was previously interviewed in the household survey. In case that person was not available, enumerators selected the closest family member present. In few cases we interviewed households, which had been sampled for the baseline household survey but had not been available then. For these participants (about $5 \%$ of the total) we miss baseline information on expenditure, financial situation and experienced shocks.
} 
site from beginning till end without making contact to the outside.

Overall sample description and covariate balance. Our sample contains $60 \%$ male and $40 \%$ female respondents. On average respondents are 54 years old and had about 5.5 years of schooling. Respondents have moderate basic algebra skills (3.3 out of five exercises were solved correctly) and are overconfident with respect to these skills, on average believing that they solved 4.1 exercises correctly. Skills in percentage calculation are low with on average 1.7 exercises out of five solved correctly. Respondents are moderately risk-averse with an average willingness to accept 96 Baht for a 50-50 chance of winning 300 Baht or nothing. About $70 \%$ of the participants live in a household which experienced a negative shock during the last three years and $81 \%$ live in a household that have debt.

On average, households spent a total of about 48,000 Baht or 1,990 \$ (PPP) per capita over the past 12 months, of which they devoted $2 \%$ on lottery. At first sight spending looks moderate, however, the standard deviation of this share ranges form 4 percentage points in the control group to 6 percentage points in the treatment group. About $42 \%$ of the sample did not participate in the lottery at all ("non-players"), whereas $58 \%$ of the respondents in our sample say that they had played a lottery at least once over the past twelve months ("players"). They report that they had devoted on average about $3 \%$ of their annual household expenditure on lottery tickets. ${ }^{8}$ We classify the top quintile of lottery players in terms of lottery expenditure share as "heavy players". These 97 participants, roughly $12 \%$ of our sample, reported that their households on average spent $9 \%$ of their total expenditure on lottery participation. ${ }^{9}$ For descriptive statistics of players, heavy players and non-players,

\footnotetext{
${ }^{8}$ In total these households spent 2.2 million Baht on lottery participation. This equals about 6 percent of their total food expenditure and about 30 percent of what these households spent on education.

${ }^{9}$ These descriptive statistics are based on baseline data including all (legal and illegal) lottery activities, where approximately a quarter is spent on tickets of the TGL and three quarters are spent on illegal lottery games. These numbers exclude all other gambling activities like dice and card games, bets on cockfighting, etc. Illegal lottery is secretly organized in local communities and usually based on bidding on the last two or three digest
} 


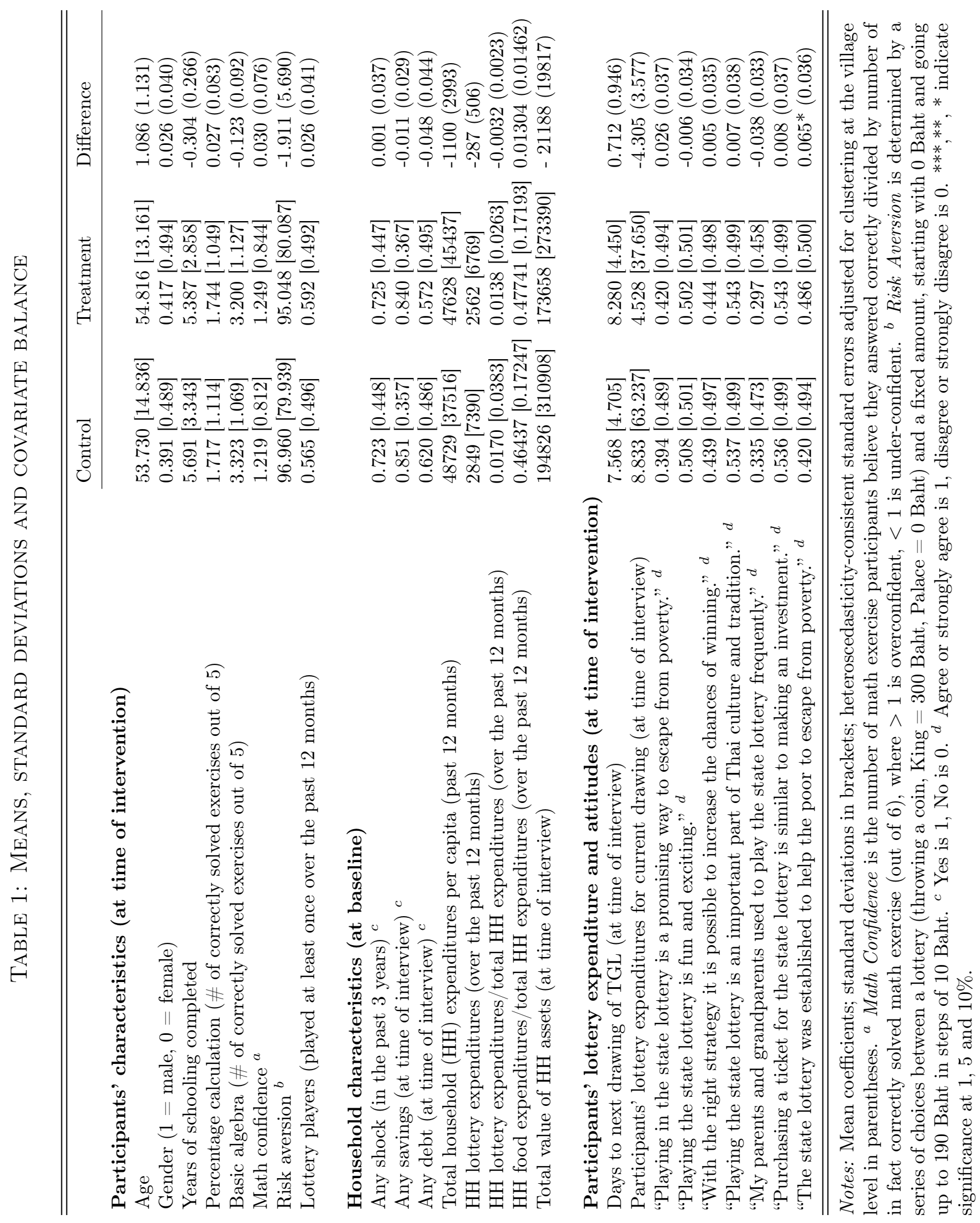


see Table A1 in Appendix 1.

Table 1 reports descriptive statistics for key baseline covariates by treatment and control group. Randomization has generated comparable groups of participants according to observable characteristics. An exception is the individual evaluation whether or not the TGL was established to help the poor to escape from poverty. Treatment and control groups differ significantly at the 10 $\%$ level. We will report robustness checks controlling for this variable in all relevant specifications below. ${ }^{10}$

\subsection{Lottery knowledge and behavior}

The Thai Government Lottery. In the TGL, tickets are issued weekly by the government lottery agency in up to 100 sets, each set containing 999,999 tickets. Every ticket has a six-digit code. Possible number combinations range from 000001 to 999999 . Tickets are usually sold in packs of two, at a fixed price of 50 Baht per single ticket (or 100 Baht per pack). With a double ticket the buyer receives two single tickets with the same six-digit number, but for two different sets. In every set of 999,999 single tickets 14,168 tickets win a total of 23 million Baht. In Table 2 we show prize categories and the number of winning tickets per set for each prize category. ${ }^{11}$

of the jackpot winning ticket numbers. Stakes and winning odds can be quite different across communities and we therefore decide to base our intervention on the official state lottery game which the majority of our participants is most familiar with. However, we are confident that our results are transferable to the illegal forms of lottery.

${ }^{10}$ The control group was interviewed on average about one day closer to the next drawing and they already spent about four Baht more on tickets for this drawing. Thus, the treatment group might be more prone to additional lottery participation because they had less time to buy tickets for the current drawing. The control group is also slightly richer than the treatment group in terms of about 12 percent higher value of physical assets. Richer households have more total resources to spend, however, total household expenditure are well balanced between groups. The lottery expenditure share of total household expenditure is slightly higher in the treatment group. All these descriptive differences are statistically insignificant.

${ }^{11}$ Winning tickets are drawn from the issued tickets. Accounting for taxes and fees (around 0.5 to $2 \%$ ), the expected value decreases by at least 0.12 and up to around 0.5 Baht. From all sets of tickets, two other prizes are drawn, amounting to 20 million Baht and 30 million 


\section{Table 2: Prize schedule of the Thai Government Lottery}

\begin{tabular}{cc}
\hline \hline $\begin{array}{c}\text { Prize } \\
\text { in Thai Baht }\end{array}$ & $\begin{array}{c}\text { Number of tickets } \\
\text { with this prize }\end{array}$ \\
\hline $2,000,000$ & 1 \\
100,000 & 5 \\
50,000 & 2 \\
40,000 & 10 \\
20,000 & 50 \\
10,000 & 100 \\
2,000 & 4,000 \\
1,000 & 10,000 \\
0 & 985,831 \\
\hline total: & 999,999 \\
\hline \hline
\end{tabular}

The numbers in the right column of Table 2 , divided by $1 \mathrm{~m}$, give the probabilities per single ticket à 50 Baht to win one of the prizes listed in the left column. The [net] expected value of gains amounts to about 23 Baht $[23-50=-27$ Baht], before taxes and fees. This excludes the additional prospect of winning one of the two bonus jackpots drawn among all sets of tickets. In each set, a total of 14,168 tickets win a prize, i.e., the probability of a single ticket to win any prize is around $1.4 \%$.

The (in)accuracy of perceptions. To proxy lottery knowledge, we solicited the probability perception of winning the jackpot, of the smallest prize and of not winning anything. To tackle the issue that rural populations in Thailand are usually not familiar with probabilities or percentage calculations we did not ask for probabilities directly. Instead we started by asking how many tickets the respondent believed were issued in one drawing of the lottery and went on to ask how many of these tickets win the jackpot of 2,000,000 Baht, a small prize of 1,000 Baht and how many of them win nothing. In

Baht, respectively. The total number of tickets issued per drawing is not published by the TGL, estimates range from 50 to 100 sets with 999,999 tickets each. The two additional jackpots increase the expected value by at most one Baht. 
TABle 3: TRue And Perceived Probabilities in the Thai

GOVERNMENT LOTTERY

\begin{tabular}{|c|c|c|c|c|c|}
\hline \multirow{2}{*}{$\begin{array}{l}\text { Lottery prize (in } \\
\text { Thai Baht) }\end{array}$} & \multirow{2}{*}{$\begin{array}{l}\text { True prob. } p \\
\text { to win this } \\
\text { prize }\end{array}$} & \multirow{2}{*}{$\begin{array}{c}\text { Median of } \\
\text { perceived } \\
\text { probability } \\
\psi\end{array}$} & \multicolumn{3}{|c|}{$\begin{array}{l}\% \text { of respondents with perceived } \\
\text { prob. }(\psi) \text { in range of }\end{array}$} \\
\hline & & & $\psi \leqq 0.99 p$ & $\begin{array}{c}0.99 p<\psi< \\
1.01 p\end{array}$ & $\psi \geqq 1.01 p$ \\
\hline & & \multicolumn{4}{|c|}{ Control Group } \\
\hline Jackpot $(2,000,000)$ & 0.000001 & 0.000007 & 22 & 14 & 64 \\
\hline Small Prize $(1,000)$ & 0.01 & 0.00013 & 74 & 5 & 21 \\
\hline Losing (0) & 0.985832 & 0.5 & 86 & 3 & 11 \\
\hline Partial Expected Gain & 12 & 20.5 & & & \\
\hline
\end{tabular}

Notes: Partial Expected Gain is calculated based on the perceived probabilities of winning the jackpot and the smallest prize. This expected gain ignores the perceived probabilities of all the other prizes that were not measured as well as the perceived probability of not winning anything. By construction it is thus different from the true expected value of a lottery ticket.

the treatment group the questions were asked after the respondents received the treatment. To create our knowledge proxies we take the ratio of winning or losing tickets, respectively, to total tickets indicated by the respondent. To overcome the problem of outliers in these variables we create dummies for each of the probabilities, which are set to 1 if the respondent's estimated winning or losing ratio (say, $\psi$ ) is close to the true probability, $p$ (and zero otherwise), i.e., if $(1-\epsilon) p<\psi<(1+\epsilon) p$. Parameter $\epsilon$ captures the admissible inaccuracy in the probability perception. Here, we report the result when we set $\epsilon=0.01$. Robustness checks using $\epsilon=0.05$ and $\epsilon=0.2$ did not change our conclusions. The descriptive statistics of the perceived probabilities reported in Table 3 show that knowledge about the odds in the TGL is actually rather imprecise among our respondents (in the control group). The true probability of winning the jackpot ( $2 \mathrm{~m}$ Baht) is one in a million. In the control group, 14 percent of the respondents had a more or less precise estimate of this probability, 22 percent underestimated it and 64 percent overestimated it widely. The median 
response was seven per million. ${ }^{12}$ Surprisingly, most respondents (74\%) underestimate the probability of winning the smallest prize of 1,000 Baht, while only $5 \%$ estimate it correctly. The remaining 21 percent of the respondents overestimate the probability. In the control group, $86 \%$ of the respondents underestimate the probability of not winning anything, while about $11 \%$ overestimate it. Only three percent estimated the losing probability correctly.

To take into account that the jackpot probability is overestimated but the small prize probability is underestimated in the median we construct an additional measure that incorporates the perception of both probabilities in one indicator for each individual. Based on the perceived probabilities of winning the jackpot and the smallest prize we calculate a "partial expected gain" for which the median is also reported in Table 3. This partial expected gain ignores the perceived probabilities of all the other prizes that were not measured as well as the perceived probability of not winning anything. By construction it differs from the true expected value of a lottery ticket. The median respondent in the control group perceives the expected value of winning the smallest and the greatest price almost twice as high as it truly is.

Does knowledge predict willingness to pay? In Table 4 we explore the baseline relationship between knowledge of the state lottery odds and the willingness to pay for lottery tickets. As respondents of the treatment group might have updated their lottery knowledge during the intervention leading to a change in the link between perception of the odds and behavior, we will only use the control group for now. We measure the willingness to pay in three different ways. We asked, first, for the household's total lottery expenditure over the past twelve months (columns (1) to (4)) and, second, for the respondent's intended spendings for the next drawing (columns (5) to (8)). ${ }^{13}$ Third, we determined the subjective ticket value of the respondents for

\footnotetext{
${ }^{12}$ Compared to the mean, the median is more immune against extreme outliers in the highest and lowest percentiles of the distribution of these variables.

${ }^{13}$ We ask for lottery expenditure over the past 12 months devoted solely to the TGL. The household data set only features lottery expenditure that do not distinguish between illegal and legal lottery spending.
} 


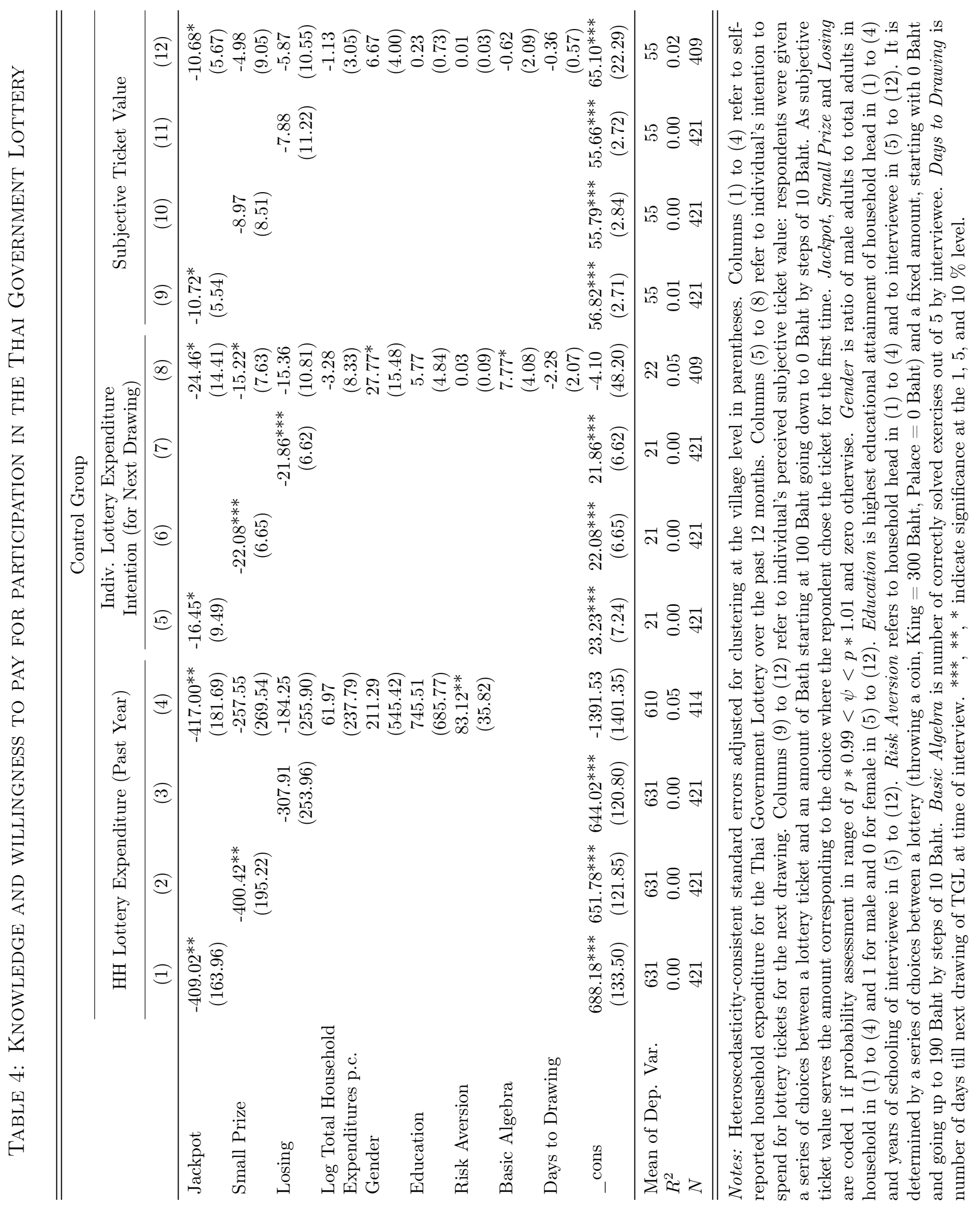


a double ticket (columns (9) to (12)). For this purpose, respondents were given a series of choices between a lottery ticket and an amount of Baht starting at 100 Baht (average market selling price) going down to 0 Baht by steps of 10 Baht. As subjective ticket value we define the amount corresponding to the choice where the respondent chose the ticket for the first time. Each choice was illustrated to the respondents by showing cards, picturing a lottery ticket and the respective Baht amount. To avoid random answers due to lack of attention, we provided respondents with a clear financial incentive. They were informed that after the questions were completed, they would draw a number from a bag to select one of the questions. For the selected question the respondent received either the money or the lottery ticket according to the choice he or she made earlier. To make sure that respondents understood the procedure enumerators were instructed to provide two carefully selected examples, see Appendix 2.

The results of the OLS regressions are shown in Table 4. For all three models we find a significant negative correlation between knowledge and playing the lottery. However, this does not establish any causal relationship. First, lottery knowledge and willingness to pay for lottery are highly endogenous because players gather knowledge during the process of participation. Second, omitted variables like attitudes and beliefs might affect both knowledge and participation. To evaluate whether the relationship really exists and is causal, we need an exogenous change in knowledge. Our intervention precisely targets this.

\section{The intervention}

Design. With the aim of improving the understanding of the odds of gains and losses in the lottery, we implement an information treatment that familiarizes participants with the probability distribution of the TGL. To avoid information overload, we focus on the most salient properties of the TGL. Since a large share of our participants is not familiar with percentage calculation or expected values and innumeracy with very large and very small 
numbers is common, providing probability information in an intelligible way was a challenging task. We opted for a visualization, using a poster of six square meters with one million dots, each representing one lottery ticket. We used colored pins to represent the prize categories. The training was provided by a local enumerator and an assistant. A training session lasted about 15 minutes and contained eleven questions read out to the participants by the trainer as well as eleven correct answers read out by the trainer and visualized by the assistant. In an extensive training enumerators were instructed to stick to the exact phrasing and to provided the information in a way that does not judge lottery participation.

Here is the intervention protocol with enumerator instructions in italics:

Trainer: Spread out poster on the floor right in front of the respondent and ask:

Q: Please see this poster with dots. How many dots are there in total?

Trainer: Encourage each participant to make a guess. After each participant made a guess provide the correct answer:

A: There are 1,000,000 dots in total on this poster.

Trainer: Show the sample ticket of the state lottery to the respondent and ask:

Please, see this ticket for the state lottery. How many tickets does the state lottery issue for each drawing of the lottery?

Trainer: Encourage each participant to make a guess. After each participant made a guess provide the correct answer: 
The state lottery issues several sets of 1,000,000 tickets for every drawing. ${ }^{14}$ The state sells as many tickets per set as are dots on this poster. Imagine every dot on the poster represents one ticket sold by the state lottery for the current drawing.

Trainer: Ask:

Some of the tickets win a prize. Most of the tickets do not win aprize. Do you know how many tickets per set win ... Baht?

Trainer: Ask for every prize category and wait until every participant made his/her guess before you give the correct answer:

- 1 ticket will win the jackpot of 2,000,000 Baht. (Assistant: fix 1 pin on poster).

- 5 tickets will win 100,000 Baht each. (Assistant: fix 5 pins on poster).

- 2 tickets will win 50,000 Baht each. (Assistant: fix 2 pins on poster).

- 10 tickets will win 40,000 Baht each. (Assistant: fix 10 dots card on poster).

- 50 tickets will win 20,000 Baht each.(Assistant: fix 50 dots card on poster).

- 100 tickets will win 10,000 Baht each. (Assistant: fix 100 dots card on poster).

\section{Trainer: Repeat:}

The colored dots on the poster represent the tickets in the state lottery that win 10.000 Baht or more. In total these are 168 tickets per set.

\footnotetext{
${ }^{14}$ For convenience and to reduce confusion during the intervention we rounded up the amount of tickets per set to 1 million.
} 
Trainer: Ask:

In addition some tickets win small prices. Do you know how many tickets per set win ... Baht?

Trainer: Ask for every prize category and wait until every participant made his/her guess before you give the correct answer:

- 4,000 tickets will win 2,000 Baht each. (Assistant: fix 4,000 dots card on poster).

- 10,000 tickets will win 1,000 Baht each. (Assistant: fix 10,000 dots card on poster).

Trainer ask:

How many tickets per set do not win anything? Can you guess a number?

Trainer: Encourage each participant to make a guess. After each participant has made a guess provide the correct answer:

All black (non-colored) dots, which you can see on this poster will not win any prize. 985.832 dots which will not win anything. This means more than 985.000 tickets per set lose.

\section{Results}

\subsection{Treatment effect on lottery knowledge}

Table 5 shows the effect of the treatment on the correct perception of the winning and losing probabilities for the full sample and the sub-sample of heavy players. Looking at the full sample, in the treatment group the share of respondents, who correctly estimate the probabilities of winning the jackpot, of 
winning the smallest prize, or of losing is higher than in the control group by, respectively, 38, 12, and 27 percentage points (columns (1), (3) and (5)). The treatment reduced the log partial expected gain by 0.59 , which implies a reduction of the partial expected gain by 45 percent, compared to the control group (column (7)). Adjusting for the covariates that were statistically significantly different in the covariate balance does not change the results (columns (2), (4), (6) and (8)). Furthermore, Table A2 in Appendix 1 shows that these results continue to hold when we control for the full set of our covariates. Compared to the control group, an additional 40 percent of the respondents in the treatment group estimated the probability of winning the jackpot correctly, an additional 13 percent of the respondents got the winning probability of the smallest prize right, and an additional 30 percent of the respondents correctly estimated the probability of losing. Adjusting for all covariates, the treatment reduces the log partial expected gain by 0.64 , which implies a reduction of the partial expected gain by about 47 percent. These estimates are within the confidence intervals of the regressions in Table 5. The median partial expected gain in the control group is 20.5 (Table 3), whereas the true partial expected gain is 12 . The reduction caused by the treatment changes the median partial expected gain of the treatment group to 11 , which is very close to the actual value.

For the heavy players, the change in partial expected gain is statistically not significant. However, the treatment induced an even stronger improvement in the knowledge variables. In the treatment group the share of heavy players who correctly estimate the probabilities of winning the jackpot, of winning the smallest prize, or of losing is higher than in the control group by, respectively, 54,23 , and 25 percentage points. Again the results are robust to controlling for covariates that were statistically significantly different in the covariate balance (columns (10), (12) and (14)) and for the full set of covariates (see Table A2 in Appendix 1).

In summary, our treatment was successful in terms of conveying information: members of the treatment group exhibit a significantly better knowledge of the odds and prospects of the TGL. 


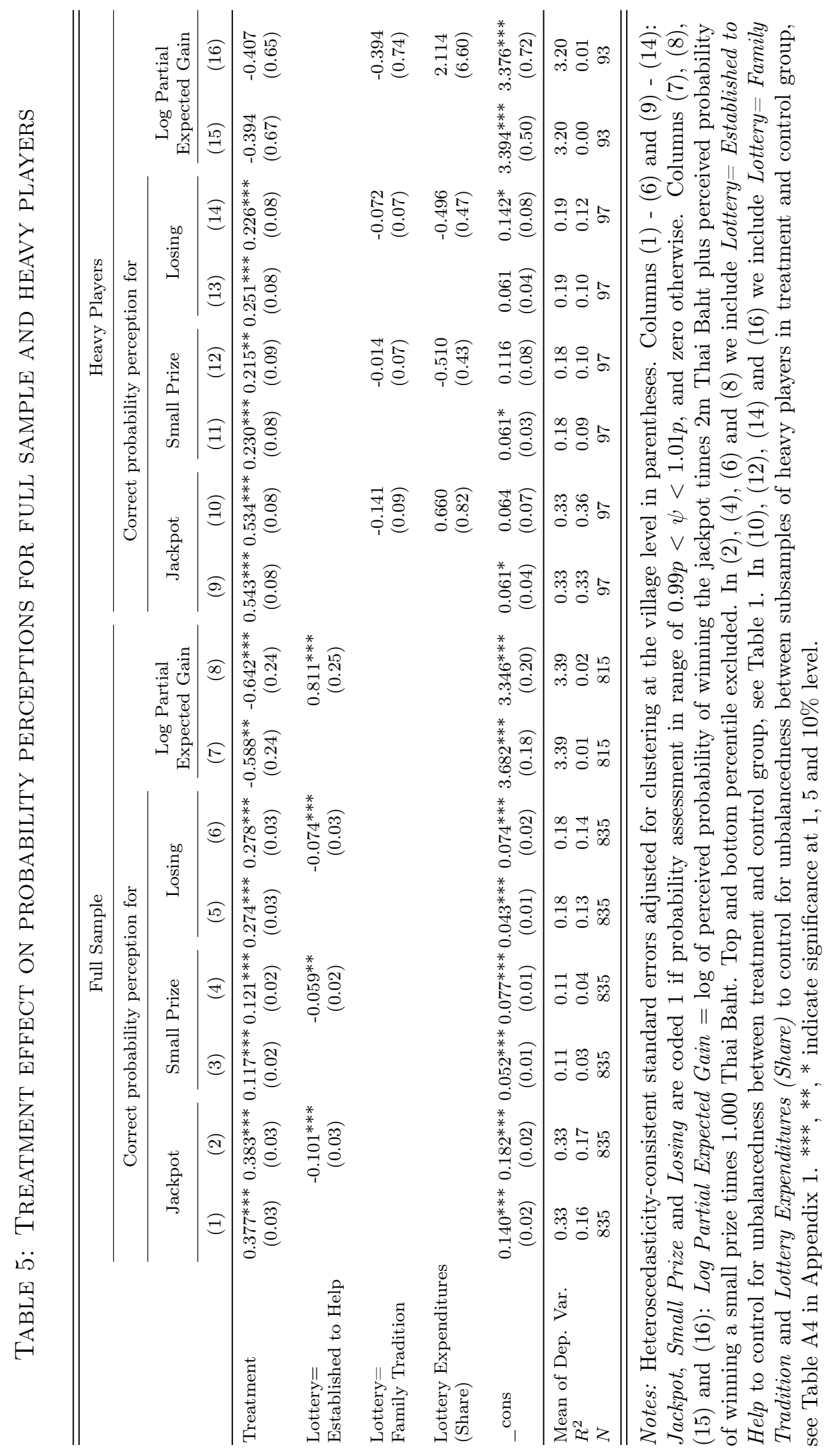




\subsection{Treatment effect on lottery participation}

Did this change in knowledge also affect the willingness to pay for lottery participation? The intended spending for lottery tickets of the next drawing is 5.4 Baht smaller in the treatment group than in the control group for the full sample (Table 6, columns (1) and (2)). As reported in columns (3) and (4), the subjective ticket value is smaller for the treatment group by about 3.8 to 4.5 Baht. However, these reductions are statistically insignificant. Controlling for the full set of covariates changes the coefficient of spending intention to 0.64 (non-significant), indicating that the treatment did not have an economically or statistically significant effect on willingness to pay (see Table A3 in Appendix 1). The treatment, thus, did not seem to trigger changes in lottery behavior on average in the full sample.

Also, all coefficients for the sub-sample of heavy players are far from significant, thus, we have to interpret them with care. However, we find it important to note that the sign of the coefficients for spending intention is even positive in the sub-sample of heavy players (columns (5) and (6)) while somewhat surprising the coefficient of the subjective ticket value is on average negative, yet showing a large standard error. We do not have information, whether the newly gained knowledge led to that unexpected situation for this specific group. A possible explanation may be that very active players might feel an increase in self-confidence regarding the understanding of the game and are somehow encouraged to try out newly conceived strategies to identify the "right" numbers in the near future. This would explain somehow, why the coefficient in the spending intentions equation is positive while it is negative in the equation on subjective ticket value: For the latter it was not possible to choose the ticket's numbers, nor was the participant able to observe them at all before making his choices.

The individual threshold of concerning lottery participation depends on many factors and is not easily determined. It is certainly harmless to purchase a couple of lottery tickets a year as a form of entertainment. This is particularly true for rural areas of developing countries where other forms of entertainment 
TABle 6: TREATMENT EFFECT ON WILlingNeSS TO PAY FOR FUlL SAMPLE AND HEAVY PLAYERS

\begin{tabular}{|c|c|c|c|c|c|c|c|c|}
\hline & \multicolumn{4}{|c|}{ Full Sample } & \multicolumn{4}{|c|}{ Heavy Players } \\
\hline & \multicolumn{2}{|c|}{$\begin{array}{c}\text { Lottery } \\
\text { Expenditure } \\
\text { Intention } \\
\end{array}$} & \multicolumn{2}{|c|}{$\begin{array}{c}\text { Subjective } \\
\text { Ticket Value }\end{array}$} & \multicolumn{2}{|c|}{$\begin{array}{c}\text { Lottery } \\
\text { Expenditure } \\
\text { Intention } \\
\end{array}$} & \multicolumn{2}{|c|}{$\begin{array}{c}\text { Subjective } \\
\text { Ticket Value }\end{array}$} \\
\hline & (1) & $(2)$ & (3) & (4) & (5) & $(6)$ & (7) & (8) \\
\hline Treatment & $\begin{array}{l}-5.39 \\
(7.60)\end{array}$ & $\begin{array}{l}-5.45 \\
(7.82)\end{array}$ & $\begin{array}{l}-3.77 \\
(3.79)\end{array}$ & $\begin{array}{l}-4.46 \\
(3.72)\end{array}$ & $\begin{array}{l}12.35 \\
(14.52)\end{array}$ & $\begin{array}{c}11.12 \\
(13.35)\end{array}$ & $\begin{array}{l}-9.96 \\
(9.10)\end{array}$ & $\begin{array}{l}-3.54 \\
(9.20)\end{array}$ \\
\hline Lottery= Established to Help & & $\begin{array}{c}0.85 \\
(8.22)\end{array}$ & & $\begin{array}{c}10.57^{* * *} \\
(3.00)\end{array}$ & & & & \\
\hline Lottery $=$ Family Tradition & & & & & & $\begin{array}{c}0.89 \\
(12.14)\end{array}$ & & $\begin{array}{c}20.95^{* *} \\
(8.26)\end{array}$ \\
\hline Lottery Expenditures (Share) & & & & & & $\begin{array}{l}-55.74 \\
(60.45)\end{array}$ & & $\begin{array}{l}108.97 \\
(84.74)\end{array}$ \\
\hline${ }_{-}$cons & $\begin{array}{c}20.93^{* * *} \\
(6.32)\end{array}$ & $\begin{array}{c}20.57^{* * *} \\
(6.36)\end{array}$ & $\begin{array}{c}55.32^{* * *} \\
(2.72)\end{array}$ & $\begin{array}{c}* 50.88^{* * * *} \\
(3.17)\end{array}$ & $\begin{array}{l}12.65 \\
(9.11)\end{array}$ & $\begin{array}{l}17.55^{*} \\
(9.61)\end{array}$ & $\begin{array}{c}62.04^{* * *} \\
(6.10)\end{array}$ & $\begin{array}{c}41.82^{* * *} \\
(9.90)\end{array}$ \\
\hline Mean of Dep. Var. & 18 & 18 & 53 & 53 & 19 & 19 & 57 & 57 \\
\hline$R^{2}$ & 0.00 & 0.00 & 0.00 & 0.02 & 0.01 & 0.01 & 0.01 & 0.10 \\
\hline$N$ & 835 & 835 & 835 & 835 & 97 & 97 & 97 & 97 \\
\hline
\end{tabular}

Notes: Heteroscedasticity-consistent standard errors adjusted for clustering at the village level in parentheses. Columns (1), (2), (5) and (6) refer to intention to spend for lottery tickets for the next drawing. Columns (3), (4), (7) and (8) refer to individual perceived subjective ticket value: respondents were given a series of choices between a lottery ticket and an amount of Bath starting at 100 Baht going down to 0 Baht by steps of 10 Baht. As subjective ticket value serves the amount corresponding to the choice where the respondent chose the ticket for the first time. In (2) and (4) we include Lottery = Established to Help because unbalancedness between treatment and control group, see Table 1. In (6) and (8) we include Lottery= Family Tradition and Lottery Expenditures (Share) because unbalancedness between heavy players of treatment and control group, see Table A4 in Appendix 1. ${ }^{* * *},{ }^{* *}, *$ indicate significance at 1,5 and $10 \%$ level. 
are rather limited. The share of expenditure devoted to lottery, however, certainly matters. In particular, if the extensively consuming household lives below poverty line or is vulnerable to fall back into poverty. Parts of our sample belong to that group of consumers. For these households a change in gambling behavior might be desirable. Our results in the subgroup analysis show however, that our information even may have had the opposite effect, and in particular on that group of participants at greatest risk. This might be an important lesson to initiators of future information campaigns to carefully consider the mechanisms of behavioral change when designing their interventions. The treatment may have caused other effects, apart from the intended provision of better information to the participants. ${ }^{15}$ Despite careful training of the enumerators, the intervention might have changed the subjective social norms of the participants towards lottery participation, leading to a more honest statement of intentions. Similarly, the treatment might have been subliminally perceived as an advertisement in some and as a warning in other cases, leading to more explorative or more cautious behavior.

\subsection{Instrumental variable approach}

As a last exercise we will explore the relationship between knowledge and willingness to pay a bit further, using the treatment indicator as an instrument for our different knowledge measures. Provided that knowledge is the only channel through which the intervention might influence willingness to pay, this exercise might serve as further evidence to investigate whether lottery knowledge is a predictor for willingness to pay for lottery participation. Of course, the results have to be interpreted with caution as we cannot prove that the exclusion restriction actually holds. The intervention may have had an impact on lottery spending intention and subjective ticket value not only through knowledge but, for instance, due to a shift of social norms, a change

\footnotetext{
${ }^{15}$ We cannot rule out an Hawthorne effect, i.e. the wish of the participant to adjust his or her behavior to what he thinks would please the enumerator. Yet, we are confident that the careful training of interviewers, eliminated this bias to the extent possible.
} 
in attitude towards lottery, or a Hawthorne effect, as discussed in the previous section. In this case the exclusion restriction would be violated and it is not possible to interpret the IV regressions as causal from knowledge to behavior.

Table 7 presents IV estimates of behavior on the four knowledge indicators. The first eight columns show again the full sample, while the last eight columns show the sub-sample of heavy players. In the bottom of the table we report F-statistics of the first stage. In the full sample specifications, the instrument is strong except for those which use log partial expected gain as the instrumented variable. For the sub-sample specifications, the instrument is strong for Jackpot probability knowledge and acceptable for small prize and losing probability knowledge, while it is extremely weak for specifications using log partial expected gain as the instrumented variable. Therefore, we will neglect all specifications that instrument for partial expected gain. The other IV estimates imply that there is no statistically significant effect on the willingness to pay for lottery participation for those affected by the provided information. The results are consistent with the signs of the treatment indicator coefficients in Table 6, yet the magnitude is somewhat larger. However, none of the estimates is statistically significant.

In summary, the information acquired in the treatment group did not significantly affect respondent's choices compared to the control group.

\section{Discussion and conclusion}

Understanding to what extent the willingness to purchase (loss-making) lottery tickets depends on people's knowledge about the structure and the odds of the game matters in various contexts: for regulatory and social policy, for lottery design, or for the theory of choice under uncertainty. Lottery knowledge is highly endogenous with lottery participation and, thus, former studies using OLS or fixed effects models were not able to convincingly test for a causal relationship between the two variables. We tried to shed some light on this issue by conducting a randomized controlled experiment on the Thai 


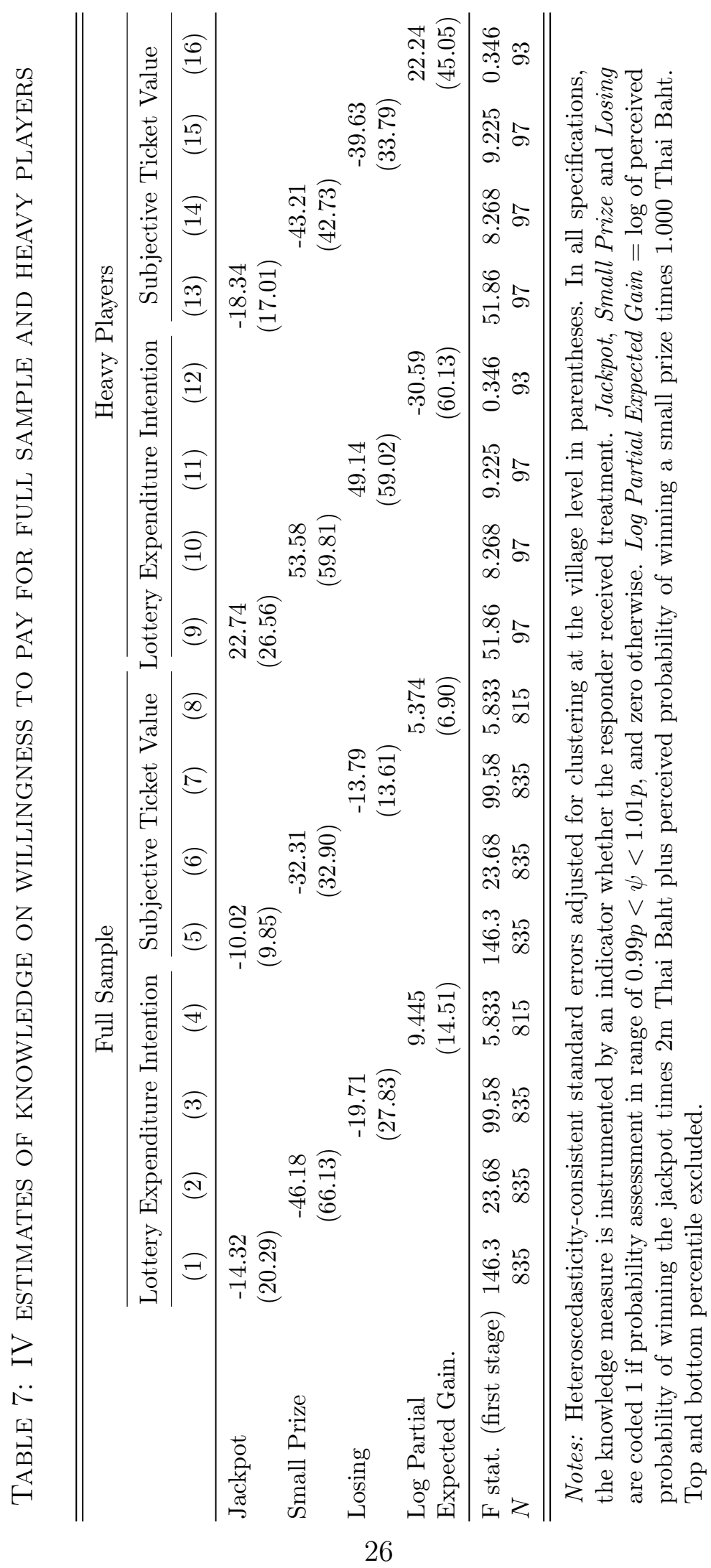


Government Lottery to exogenously change the knowledge on the odds of the lottery game of randomly selected villagers in rural Thailand. Being exposed to an information treatment, individuals showed a much better quantitative understanding of the odds of the TGL than similar, but untreated individuals. Yet, this success in teaching did not translate into a statistically or economically significant reduction in the willingness to pay for lottery tickets of our treatment group compared to the control group. Similar to former studies we find a negative correlation between the two variables in our baseline data. Former studies, however, conclude that a negative relation between the two variables imply that a change in knowledge will change participation behavior. Analyzing lottery behavior after an exogenous change in knowledge, however, contradicts this implication. There are several possible explanations for our finding.

One explanation might be that the willingness to pay for a lottery ticket is more or less inelastic to winning and losing probabilities (or the expected value of the ticket). This would imply that other factors, such as the entertainment value of a lottery ticket, or emotional and social motifs determine the willingness to pay. Poor households might believe that it requires a "big push" to significantly improve their economic situation. A lottery ticket is one of the very few potential gateways for these households to experience such a big push. In case this is their main motivation, they might not distinguish between tiny and tinier probabilities. Any chance, no matter how tiny it may be, to experience a massive improvement might look more appealing than the small improvements that alternative investments or expenditure choices would yield. If this was true, additional information about large potential returns to perhaps underestimated alternative investments might be able to change behavior and eventually crowd out lottery expenditure, but pure information on lottery odds does not.

Generalizing a bit further, what really drives behavior might not be knowledge alone (in the sense of consciously accessible representations of situations), but cognitive processes working through the channels of beliefs as suggested by the Theory of Planned Behavior. The theory, first published by Ajzen (1991), is a 
well established concept in psychological science of explaining the mechanisms of behavioral change. In particular, it suggests that any behavior is determined by intention, which in turn is formed by attitude towards, subjective norms of and perceived control over the particular behavior. The theory has been tested in various settings, including e. g. a number of information interventions, and has been found to satisfyingly explain in which case information has the power to change behavior (see e.g. Ajzen, Joyce, Sheikh, and Cote (2011)). As a rule of thumb, information is most likely to trigger behavioral change, if it is able to change one or all of the underlying beliefs for the three mentioned action relevant categories above in a sufficiently strong magnitude. Accumulation of correct knowledge, however, might be irrelevant in the process of inducing behavioral change according to the theory. To make information effective in our specific case of changing lottery consumption, it might have to affect the belief that it is possible to change the winning odds of a ticket by e.g. personal luck, the right strategy of picking numbers or attitudes towards lotteries or the government in general- which we did not target for in our intervention. In the light of TPB, it might be necessary to reconsider the strategies of designing information interventions all together. Knowledge campaigns conducted by economists sometimes lack insights of psychological science. It might be worthwhile to join forces of both fields to more efficiently target behavioral changes and through that stimulate individual (economic) development. 


\section{References}

AJZEN, I. (1991): "The theory of planned behavior," Organizational behavior and human decision processes, 50(2), 179-211.

Ajzen, I., N. Joyce, S. Sheikh, And N. G. Cote (2011): "Knowledge and the Prediction of Behavior: The Role of Information Accuracy in the Theory of Planned Behavior," Basic and Applied Social Psychology, 33(2), $101-117$.

Banerjee, A. V., And E. Duflo (2007): "The Economic Lives of the Poor.," Journal of Economic Perspectives, 21(1), 141-167.

Chong, A., M. Gonzalez-Navarro, D. Karlan, and M. Valdivia (2013): "Effectiveness and Spillovers of Online Sex Education: Evidence from a Randomized Evaluation in Colombian Public Schools," NBER Working Paper, 18776.

Chong, A., D. Karlan, J. Shapiro, and J. Zinman (2013): “(Ineffective) messages to encourage recycling: evidence from a randomized evaluation in Peru," World Bank Policy Research Working Paper, 6548.

Clotfelter, C. T., And P. J. Cook (1989): "The demand for lottery products," NBER Working Paper, 2928.

- (1990): "On the economics of state lotteries," The Journal of Economic Perspectives, 4(4), 105-119.

Duflo, E., And E. SAEz (2003): "The role of information and social interactions in retirement plan decisions: Evidence from a randomized experiment," The Quarterly Journal of Economics, 118(3), 815-842.

Dupas, P. (2011): "Do Teenagers Respond to HIV Risk Information? Evidence from a Field Experiment in Kenya," American Economic Journal: Applied Economics, 3(1), 1-34. 
Hardeweg, B., S. Klasen, and H. Waibel (2013): "Establishing a database for vulnerability assessment," Vulnerability to Poverty - Theory, Measurement, and Determinants., pp. pp. 50-79.

HoRnik, R. C. (1989): "The knowledge-behavior gap in public information campaigns: a development communication view.," Sage annual reviews of communication research, 18.

Jamison, J. C., D. Karlan, and P. Raffler (2013): "Mixed Method Evaluation of a Passive mHealth Sexual Information Texting Service in Uganda," NBER Working Paper, 19107.

Jensen, R. (2010): "The (perceived) returns to education and the demand for schooling," The Quarterly Journal of Economics, 125(2), 515-548.

Karlan, D., And M. Valdivia (2011): "Teaching entrepreneurship: Impact of business training on microfinance clients and institutions," Review of Economics and Statistics, 93(2), 510-527.

KeARney, M. S. (2005): "State lotteries and consumer behavior," Journal of Public Economics, 89(11-12), 2269-2299.

Kocher, M., M. KraWczyk, and F. van Winden (2013): "Let me dream on! Anticipatory emotions and preference for timing in lotteries," Journal of Economic Behavior \&3 Organization.

Matheson, V. A., And K. R. Grote (2004): "Lotto fever: do lottery players act rationally around large jackpots?," Economics Letters, 83(2), 233-237.

Rogers, P., And P. Webley (2001): "It Could Be Us!": Cognitive and Social Psychological Factors in UK National Lottery Play," Applied Psychology, 50(1), 181-199.

Stearns, J. M., and S. Borna (1995): "The ethics of lottery advertising: Issues and evidence," Journal of Business Ethics, 14(1), 43-51. 
Tversky, A., And D. Kahneman (1974): "Judgment under uncertainty: Heuristics and biases," Science, 185(4157), 1124-1131.

WagenaAR, W. A. (1988): Paradoxes of gambling behaviour. Lawrence Erlbaum Associates, Inc.

Wisdom, J., J. S. Downs, and G. Loewenstein (2010): "Promoting healthy choices: Information versus convenience," American Economic Journal: Applied Economics, 2, 164-178. 


\section{Appendix 1}

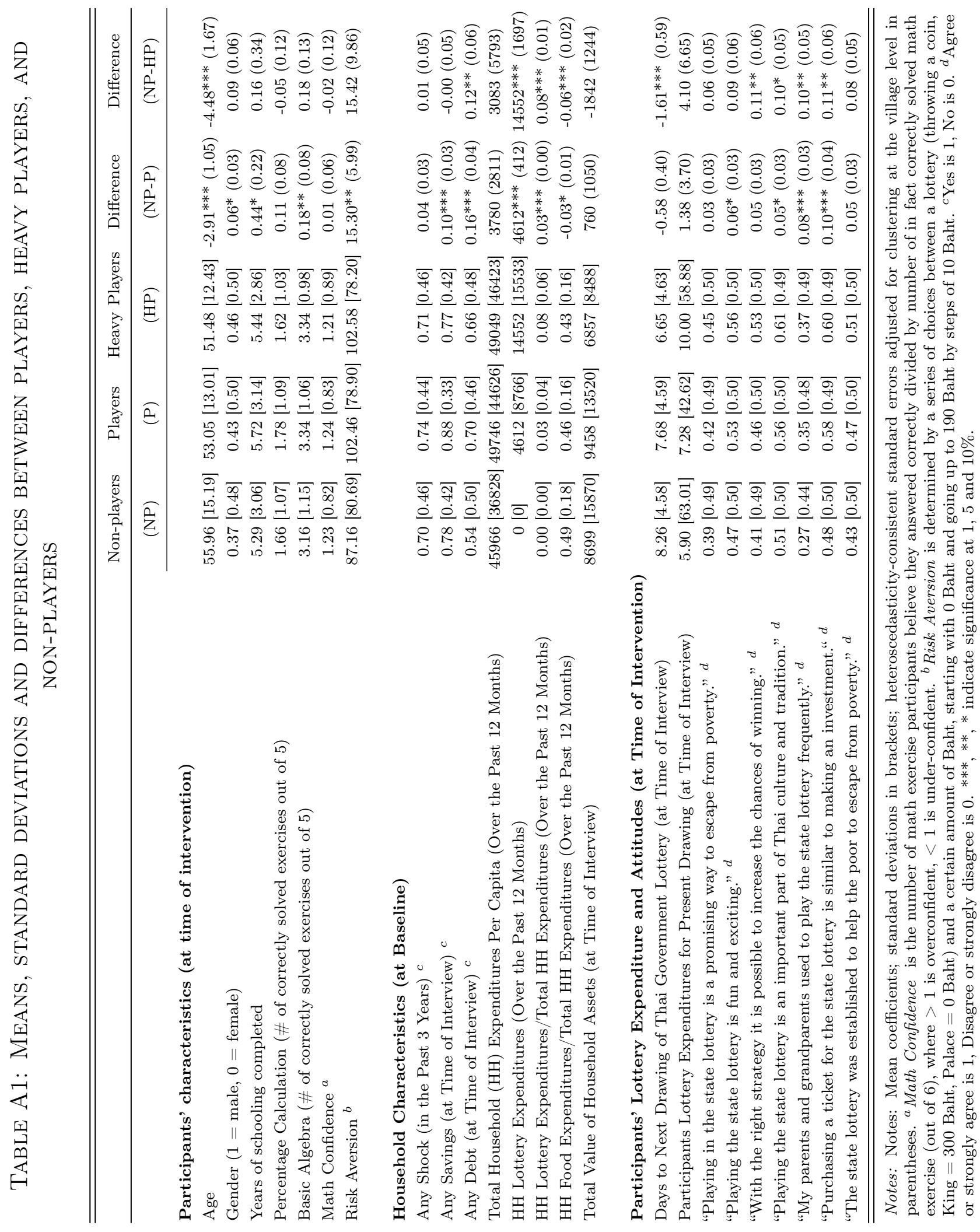




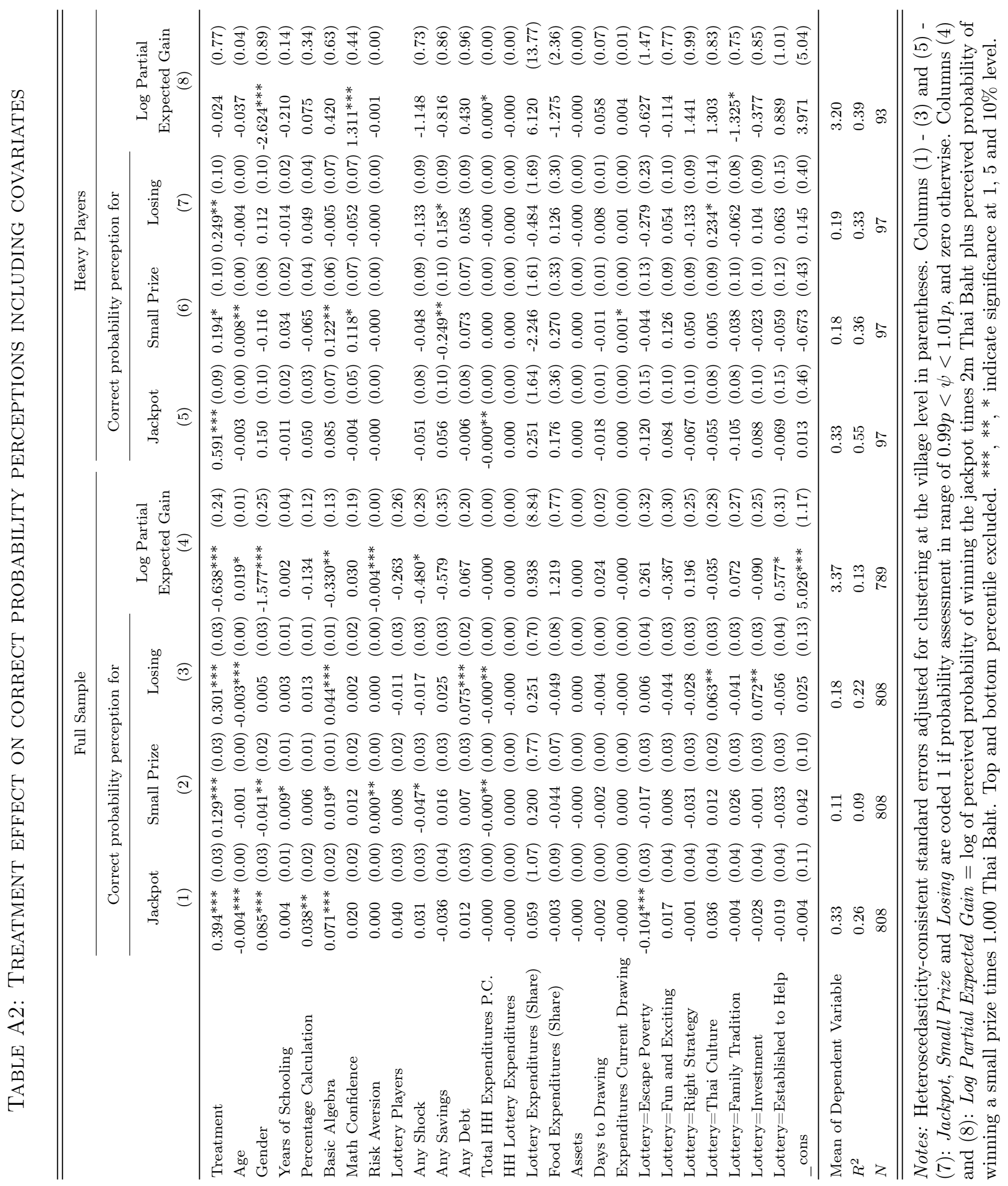




\section{TABle A3: TREATMent EFFECT On Willingness TO PAY INCLUDing COVARIATES}

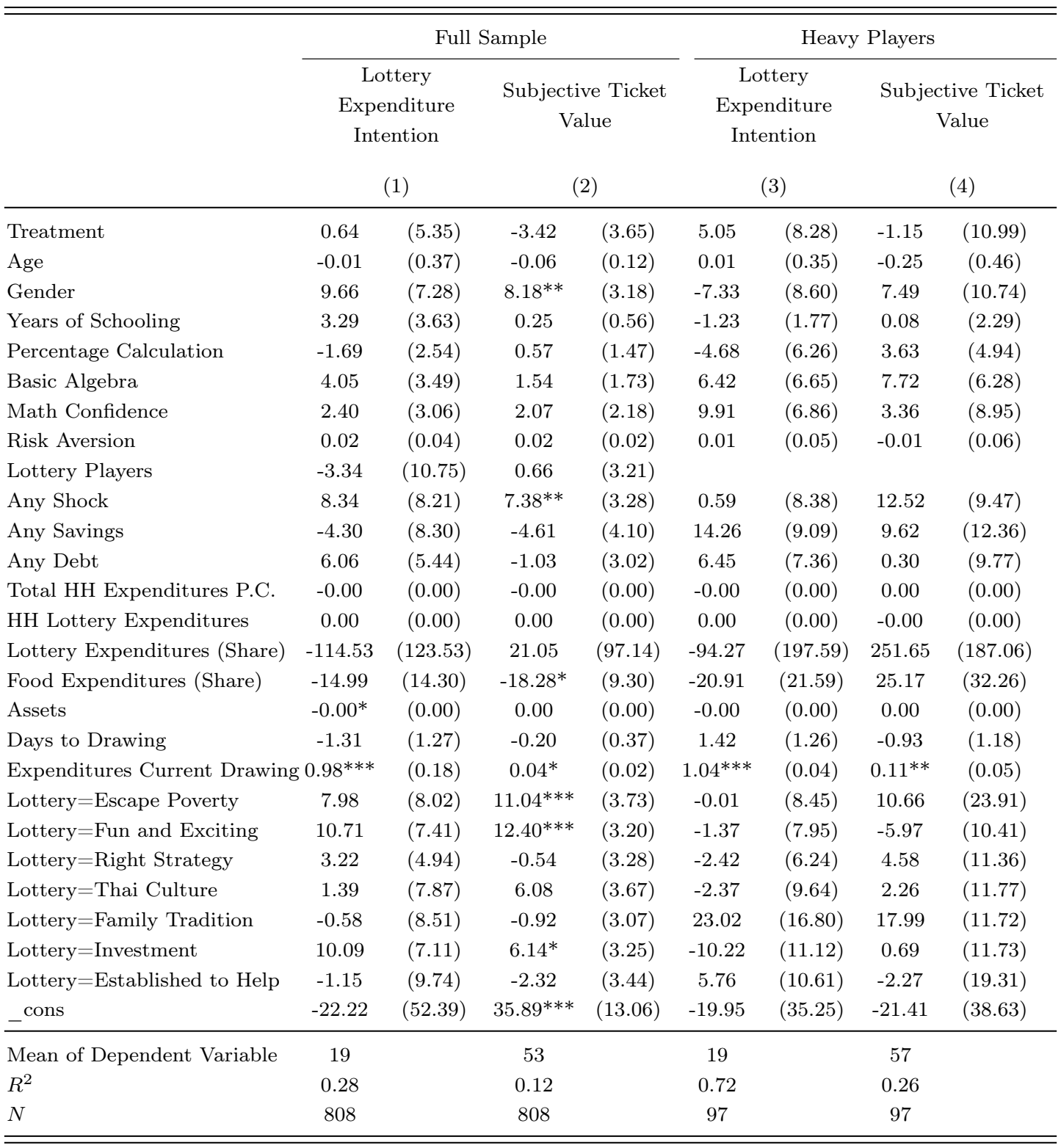

Notes: Heteroscedasticity-consistent standard errors adjusted for clustering at the village level in parentheses. Columns (1) and (3) refer to intention to spend for lottery tickets for the next drawing. Columns (2) and (4) refer to individual perceived subjective ticket value: respondents were given a series of choices between a lottery ticket and an amount of Bath starting at 100 Baht going down to 0 Baht by steps of 10 Baht. As subjective ticket value serves the amount corresponding to the choice where the respondent chose the ticket for the first time. All regressions include the full set of covariates. $* * *, * *, *$ indicate significance at 1,5 and $10 \%$ level. 


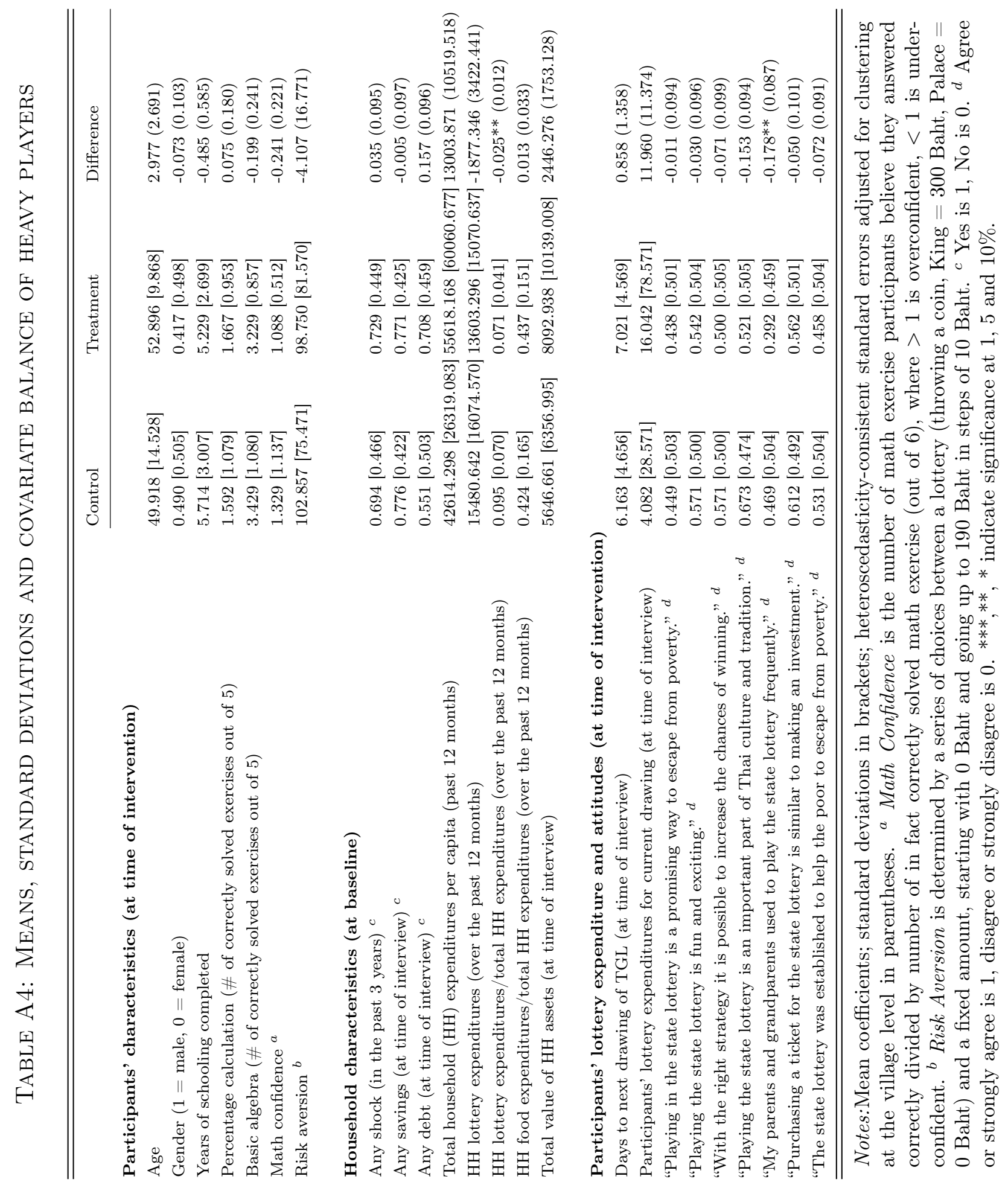




\section{Appendix 2}

\section{Instructions (Enumerator: read out)}

Now we want to play a simple game with you. In this game we want to find out about your preference regarding the state lottery. In this game you will receive money or a real lottery ticket. What you will receive depends partly on your decision and partly on chance.

There is a series of 12 questions. (Enumerator: show book of 12 show cards) In each question we will offer you two options: offer A and offer B. We would like you to choose either offer A or offer B for each question. We will note your choice for each question in this record sheet. (Enumerator: show record sheet) After we completed the record sheet, you will draw one number from this bag. (Enumerator show bag with numbers). The bag contains the numbers 1 to 12 . You draw one number to select one question out of the 12 questions. For the selected question you will receive offer A or offer B according to the choice you made earlier.

For example:

If you draw the number 1 , you will receive 100 Baht if you chose option A. You receive a lottery ticket if you chose option B. If you draw the number 12, you will receive 0 Baht if you chose option A. You receive a lottery ticket and 10 Baht if you chose option B. You should choose for each card, which offer you would rather like to receive.

(Enumerator: Start now to show each of the 12 choices to the respondent using your book of show cards.)

\begin{tabular}{|c|c|l|c|c|c|l|}
\hline & & & A & & B & \\
\hline $\mathbf{1}$ & 100 & Baht & & or & & Lottery Ticket \\
\hline $\mathbf{2}$ & 90 & Baht & & or & & Lottery Ticket \\
\hline $\mathbf{3}$ & 80 & Baht & & or & & Lottery Ticket \\
\hline $\mathbf{4}$ & 70 & Baht & & or & & Lottery Ticket \\
\hline $\mathbf{5}$ & 60 & Baht & & or & & Lottery Ticket \\
\hline $\mathbf{6}$ & 50 & Baht & & or & & Lottery Ticket \\
\hline $\mathbf{7}$ & 40 & Baht & & or & & Lottery Ticket \\
\hline $\mathbf{8}$ & 30 & Baht & & or & & Lottery Ticket \\
\hline $\mathbf{9}$ & 20 & Baht & & or & & Lottery Ticket \\
\hline $\mathbf{1 0}$ & 10 & Baht & & or & & Lottery Ticket \\
\hline $\mathbf{1 1}$ & 0 & Baht & & or & & Lottery Ticket \\
\hline $\mathbf{1 2}$ & 0 & Baht & & or & & Lottery Ticket \& 10 Baht \\
\hline
\end{tabular}

